\title{
DESCRIÇÃO TÉCNICA E MODO DE OPERAÇÃO DAS ARTES DE PESCA ARTESANAIS DO CAMARÃO-ROSA NO ESTUÁRIO DA LAGOA DOS PATOS, RIO GRANDE DO SUL, BRASIL.
}

\author{
RAMON AUGUSTO BENEDET ${ }^{1}$, DENIS DOLCI ${ }^{2}$ \& FERNANDO D'INCAO ${ }^{1}$ \\ ${ }^{1}$ Universidade Federal do Rio Grande (FURG) - Instituto de Oceanografia - Laboratório de Crustáceos Decápodes, Caixa Postal 474 - CEP \\ 96201-900 - Rio Grande - RS - Brasil. ${ }^{2}$ Laboratório de Tecnologia Pesqueira; ${ }^{3}$ ramonbenedet@hotmail.com
}

\begin{abstract}
A pesca artesanal é uma das principais atividades econômicas no estuário da Lagoa dos Patos e o camarão-rosa é uma das espécies mais exploradas. Este estudo tem como objetivos descrever as artes de pesca empregadas na pesca artesanal do camarão-rosa e 0 modo de operação das mesmas pelos pescadores. Os dados utilizados para as análises deste trabalho provêm de entrevistas a 15 pescadores e do acompanhamento da atividade pesqueira em 471 oportunidades, abrangendo todas as artes e áreas de pesca no período entre 1999 e 2004. Foram confeccionados desenhos técnicos das artes de pesca empregadas na captura do camarão-rosa seguindo as recomendações da FAO e suas principais características foram descritas. Seis tipos de artes são utilizadas na área, sendo quatro delas consideradas ilegais pela atual legislação. As artes de pesca legalizadas são as redes de saquinho e saco. O saquinho é a rede mais utilizada, caracterizada pelo uso de um atrativo luminoso e a presença de funis no ensacador da rede para manter o pescado aprisionado. As redes de saco são fixadas em zonas de canal e pescam utilizando a força das correntes de vazante. As redes proibidas são as de arrasto manual (coca e berimbau) ou motorizado (portas e pauzinho). As redes possuem diversas formas de confecção com cortes e materiais distintos. O uso de malhas inferiores ao permitido é comum e a atual legislação é falha em vários aspectos do uso da principal rede utilizada (saquinho).
\end{abstract}

RESUMO

PALAVRAS-CHAVE: artes de pesca, camarão-rosa, Farfantepenaeus paulensis, Lagoa dos Patos, pesca artesanal.

\section{ABSTRACT}

The artisanal fishery is one of the main economic activities in the Patos Lagoon estuary and the pink shrimp is one of the more explored species. The study objective was the description of the fishing gears employed and how they are operated at the artisanal pink shrimp fishery. The data used for the analyze come from interviews with 15 fishermen and by the accompaniment of the fishing activity in 471 places, enclosing all gears and fish areas at the period between 1999 and 2004. Technical drawings of the fishing gears used at pink shrimp fishery are provided, following recommendations of FAO, and its main characteristics had been described. Six different types of fishing gears are employed in the area, four of them considered illegal according to the current legislation. The legalized fishing gears are the fyke nets ("saquinho") and stow nets ("saco"). "Saquinho" is the most used; it is characterized for the use of luminous attraction and the presence of funnels in the sack to maintain the shrimp trapped. "Saco" nets are set in canal zones and, its fishing action is achieved using ebb tide currents. The forbidden nets are all trawling gears, manual ("coca" and "berimbau") or motorized (otter trawl and "pauzinho"), with nevertheless are freely utilized in the whole estuarine area. Nets manufacturing cuts and the material utilized are diverse. The use of mesh sizes below the minimum legal size is widespread, and there are several faults in the law that regulates the use of fyke nets.

KEY WORDS: fishing gears, pink shrimp, Farfantepenaeus paulensis, Patos Lagoon, artisanal fishery

\section{INTRODUÇÃO}

\section{O camarão-rosa Farfantepenaeus paulensis}

(Pérez Farfante, 1967) é o principal recurso explorado pela pesca artesanal na Lagoa dos Patos (D'Incao, 1991). A pesca ocorre, principalmente, nas enseadas rasas da região estuarina, as quais são denominadas de "sacos". A legislação vigente (Instrução Normativa Conjunta 3/2004 da Secretaria Especial de Aqüicultura e Pesca - SEAP e do Ministério do Meio Ambiente - MMA) permite a pesca com saquinho durante os meses de fevereiro a maio. Mesmo assim, sabe-se que existe o uso de outras artes de pesca e que o período de pesca não é respeitado.

O conhecimento empírico e as artes de pesca relativamente simples são algumas características dos pescadores artesanais (Diegues, 1993a) que, com o passar dos anos, vêm aperfeiçoando seus instrumentos e métodos de pesca com o intuito de aumentar seus rendimentos (Fernö \& Olsen, 1994).
As artes de pesca utilizadas no estuário da Lagoa dos Patos ainda não foram estudadas quanto à estrutura e à forma de atuação. Os trabalhos que citam estas artes estão baseados na descrição da pesca de outras regiões (Gamba, 1984) ou relatados em trabalhos voltados para aspectos de biologia pesqueira (Marques, 1997; Almeida \& D'Incao, 1999).

$O$ presente trabalho tem como objetivo descrever os apetrechos e os métodos de pesca artesanais empregados na captura do camarão-rosa.

\section{MATERIAL E MÉTODOS}

\section{Área de estudo \\ O estuário da Lagoa dos Patos (Fig. 01) localiza-se na planície costeira do Estado do Rio Grande do Sul no extremo sul do Brasil. Inicia-se no canal da barra de Rio Grande e estende-se até uma linha imaginária que liga a Ponta dos Lençóis $\left(31^{\circ} 41^{\prime} \mathrm{S}, 52^{\circ} 02^{\prime} \mathrm{W}\right)$ até a Ponta da Feitoria (31 ${ }^{\circ} 48^{\prime} \mathrm{S}$,}


$51^{\circ 52} \mathrm{~W}$ ), totalizando $971 \mathrm{~km}^{2}$ (Calliari, 1980).

Essa região possui um grande número de enseadas rasas com menos de três metros de profundidade e bancos de areia, os quais representam $80 \%$ da região (Coutinho \& Seeliger,
1986). É formada, principalmente, por sedimentos de argila e silte, típicos das zonas mais profundas e das enseadas rasas protegidas, e fundos arenosos, associados às margens e partes baixas dos bancos arenosos (Calliari, 1980).

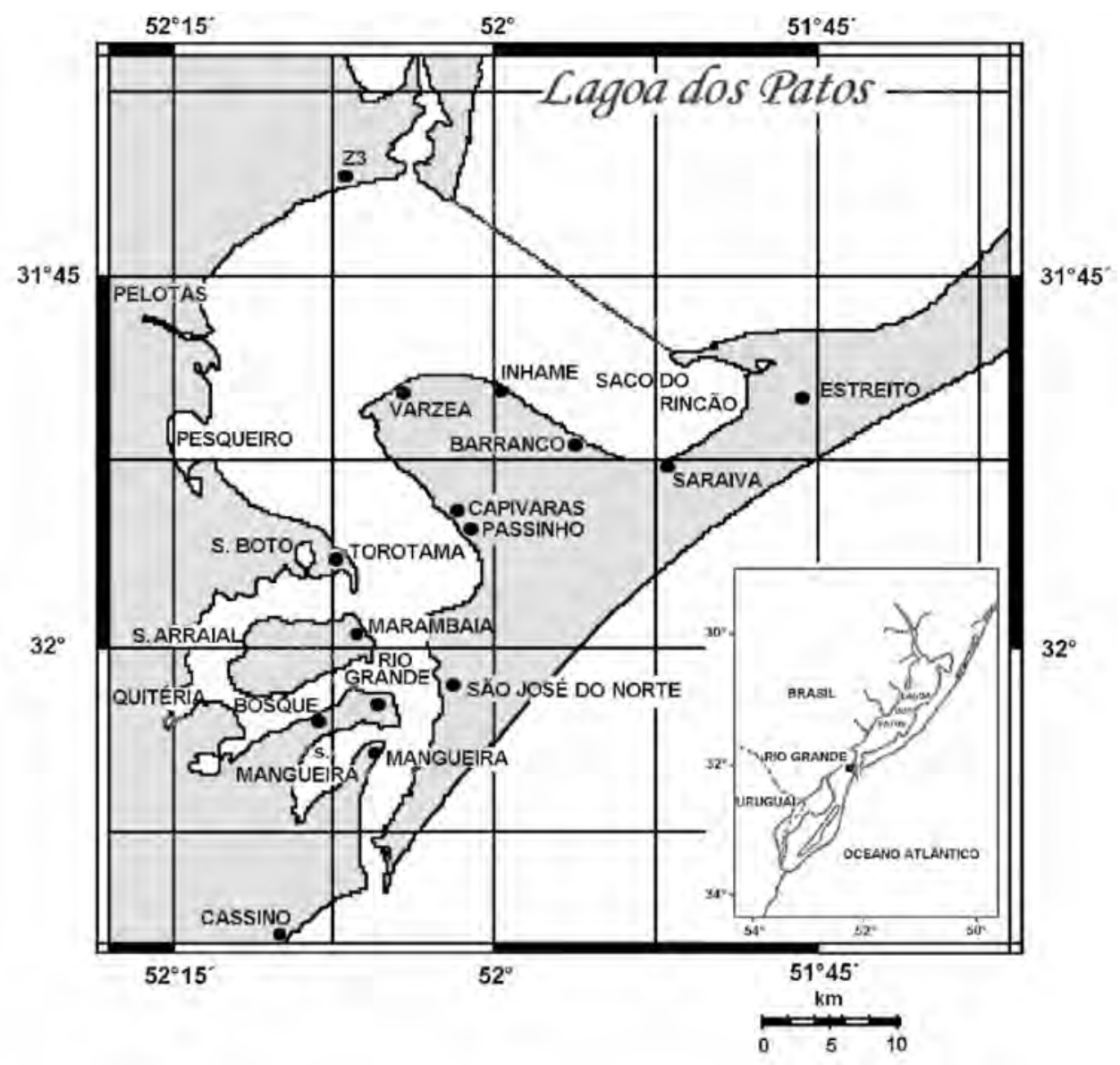

FIGURA 01. Região estuarial da Lagoa dos Patos. Estão relacionadas as principais comunidades de pescadores artesanais.

\section{Atividades de Campo}

Os dados utilizados nesse trabalho foram coletados entre os anos de 1999 e 2004, provenientes das comunidades de pesca artesanal do estuário (Fig. 01).

A caracterização dos métodos empregados na pesca foi obtida com o acompanhamento de 268 despescas de andainas de redes tipo saquinho, 64 lances de arrasto de portas, 36 despescas de andainas de redes de saco, e 103 lances de rede tipo coca e berimbau.

Para cada entrevista eram registradas as seguintes informações: local, profundidade, nome do barco e da tripulação; características estruturais das redes (tamanho, tipo, modelo, material utilizado e etc); e informações sobre os métodos de pesca que foram obtidas através de entrevistas realizadas com os pescadores durante os embarques.

Adicionalmente, 15 redeiros de 10 comunidades foram entrevistados com o objetivo de obter informações sobre os tipos de redes, métodos de confecção, características dos materiais utilizados e possíveis modificações nas redes realizadas ao longo do tempo da pesca no estuário.

Os desenhos técnicos foram confeccionados a partir de redes emprestadas pelos pescadores. Seguiram-se as recomendações da International Standard Statistical Classification of Fishing Gear 
(ISSCFG) (Nédélec \& Prado, 1990).

Para cada apetrecho foram observadas as seguintes características:

a) Panos da rede:

fios têxteis (material, numeração, diâmetro e estrutura);

número de malhas (bordo superior, bordo inferior e altura);

tamanho de malha (igual a dois lados da malha $-2 \mathrm{a})$;

coeficiente de abertura da malha;

tipos de corte.

b) Características das tralhas (comprimento, material, diâmetro e estrutura do cabo), tralha superior (características dos flutuadores) e tralha inferior (características dos lastros).

c) Informações sobre a operação de cada apetrecho.

Os diversos itens utilizados na construção das redes foram comparados com mostruários dos respectivos fabricantes e as medidas obtidas por meio de paquímetro $(0,1 \mathrm{~mm})$, trena de $30 \mathrm{~m}(1 \mathrm{~mm})$ e balança digital de $25 \mathrm{~kg}$ (1 gr).

Para a confecção dos planos das artes de pesca, o coeficiente médio de abertura vertical $\left(\mathrm{N}_{2}\right)$ foi considerado igual a 1 e o horizontal $\left(N_{1}\right)$ foi estimado com base nas seguintes relações:

$$
N_{1}=\operatorname{Cos} \beta=\frac{X}{2 a} ; \quad N_{2}=\operatorname{Sen} \beta=\frac{Y}{2 a} \text { e } \quad N_{1}^{2}+N_{2}^{2}=1
$$

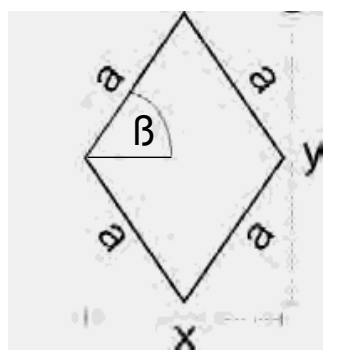

As artes de pesca foram, inicialmente, desenhadas em papel milimetrado e digitalizados pelo programa GIMP 2.2.

\section{RESULTADOS}

As artes de pesca utilizadas na captura do camarão-rosa apresentaram uma grande variedade quanto à forma e ao tamanho. Esse fato ocorre pelas distintas características ambientais de cada local ou pela formação pessoal do pescador. Quando confecciona seus apetrechos, o pescador os adapta conforme as características de sua região de pesca. Em regiões onde a concentração de algas e a hidrodinâmica são maiores, os pescadores optam por confeccionar as redes em tamanhos menores, principalmente, quando estas possuem mangas, diminuindo $o$ acúmulo de algas e a força de resistência do aparelho com a água.

A origem do pescador também influencia na forma da construção das redes. Este fato é constatado pelos diversos tipos de cortes $e$ entralhamentos encontrados num mesmo tipo de rede e na maneira de pescar, evidenciada pela forma de colocação e dos tipos de redes utilizados.

\section{Artes de pesca}

Seis diferentes artes de pesca foram identificadas e divididas em passivas (redes de espera fixadas por estacas) e ativas (redes arrastadas por embarcações a motor ou manualmente). As artes passivas são as redes de saquinho e saco, e as ativas estão representadas pelas redes de coca, berimbau, arrasto de portas e pauzinho.

\section{Artes passivas}

\subsection{Rede de saquinho - Fyke nets}

O saquinho é a rede de pesca mais utilizada por pescadores artesanais no estuário para a captura do camarão-rosa. Contagens realizadas em abril de 1999 no Saco do Rincão, mostrou a atuação de 4288 saquinhos, enquanto as demais artes de pesca não apareceram no censo.

A pesca é noturna, realizada em áreas com profundidades de 0,6 a $4 \mathrm{~m}$ e sobre diferentes tipos 
de substrato. Eventualmente, a pesca é realizada durante o dia aproveitando a turbidez da água em períodos de vento nordeste.

As redes são presas aos calões (estacas de bambu ou eucalipto), formando grupos de redes chamados de andainas. As andainas podem ter de 3 a 120 unidades (legislação permite apenas 10) e pertencem ao mesmo pescador ou grupo. A disposição das redes nas andainas pode variar: "perfiadas" quando são unidas manga a manga e as bocas voltadas para margem e para o lado oposto, alternadamente; lado a lado onde todas as bocas estão na mesma direção (Fig. 02A) ou em formato de roseira/rosa, formando um círculo com o dispositivo luminoso no centro (Fig. 02B).
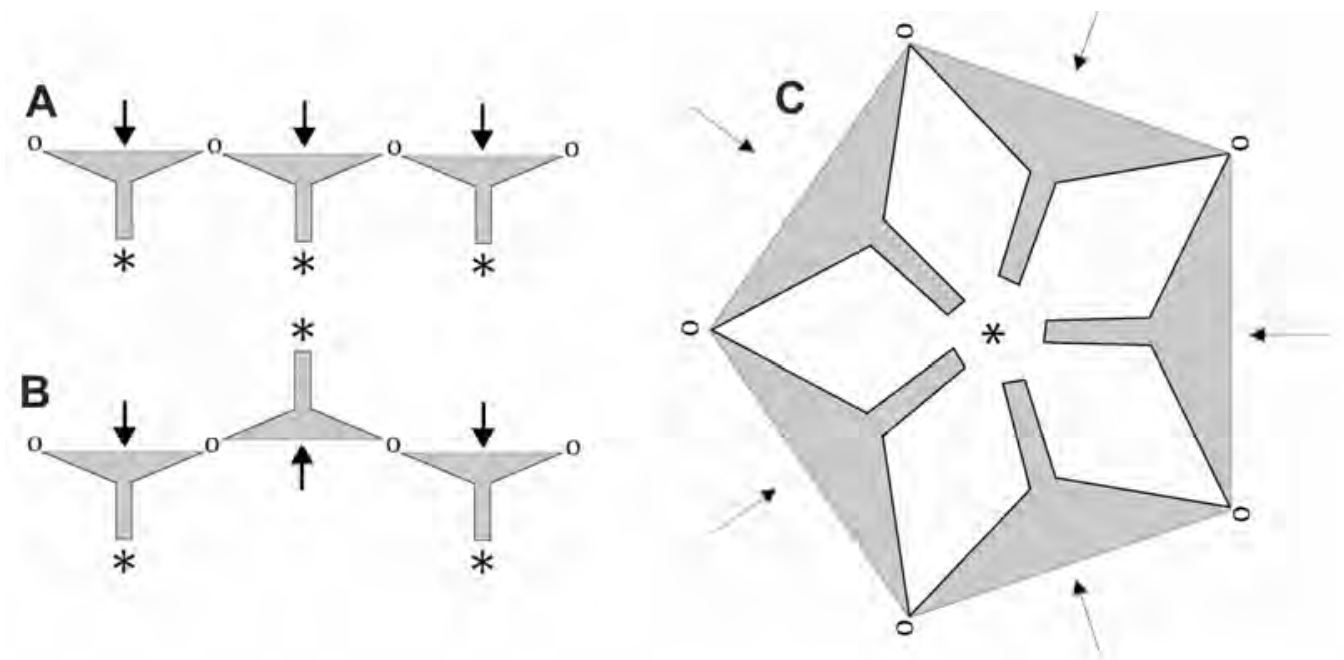

Figura 02. Esquemas da disposição das redes tipo "saquinho" nas andainas, observados no estuário da Lagoa dos Patos. A) Lado a lado; B) Perfiadas; C) Roseira, rosa ou roseta. Setas indicam o sentido de penetração dos camarões nas redes, $\mathbf{0}$ - estacas ou calões, ${ }^{*}$ - fonte luminosa (lampião a gás).

A maioria dos pescadores artesanais da llha dos Marinheiros, Saco da Mangueira, Saco do Mendanha e Saco do Silveira, utiliza as redes de saquinho na forma perfiada. Essa prática faz com que o poder de pesca das redes aumente devido às mangas estarem unidas. Assim, o lado externo da manga de uma rede funciona como uma extensão da manga da rede ao lado, dobrando o tamanho inicial da manga.

Os atrativos luminosos são colocados presos em estacas de madeira sempre na porção terminal da rede (rabicho) e o número de redes por atrativo varia de 1 a 7 , no caso do lampião a gás, e uma rede para cada atrativo, na utilização de lâmpadas de 12 v. O butijão de gás dos lampiões é recarregado diariamente após seu uso com a passagem do gás de um botijão P13 (13 kg ou 31 I) para um P2 (2 kg ou 4,8 I). Cada botijão recebe de 1,5 a $2 \mathrm{~kg}$ de gás, suficiente para utilização durante uma noite de pesca.
As baterias passam por cargas diárias em carregadores elétricos.

Após a pesca, as redes são suspensas no ar, para evitar o acúmulo de sujeira, ou retiradas e levadas para terra para evitar roubo ou diminuir seu desgaste. Passam diariamente por pequenos reparos como a costura de pequenos buracos.

A rede (Fig. 03 e 04) é formada por duas mangas e um corpo (ensacador) onde são colocados aros e válvulas (funis) para impedir a saída do pescado. O pano do ensacador é mantido armado por aros feitos de arame galvanizado, aço inox ou cobre, normalmente cobertos por fita isolante, lona plástica ou tubos plásticos finos, os quais impedem o contato com a água salgada, prevenindo a oxidação. Os aros de sustentação medem de 35 a $65 \mathrm{~cm}$ de diâmetro e os que formam a extremidade dos funis possuem de 14 a $24 \mathrm{~cm}$. O ensacador mede de 4,5 a $6,5 \mathrm{~m} \mathrm{e}$ recebe de 1 a 3 funis, sendo mais utilizado 2 . 


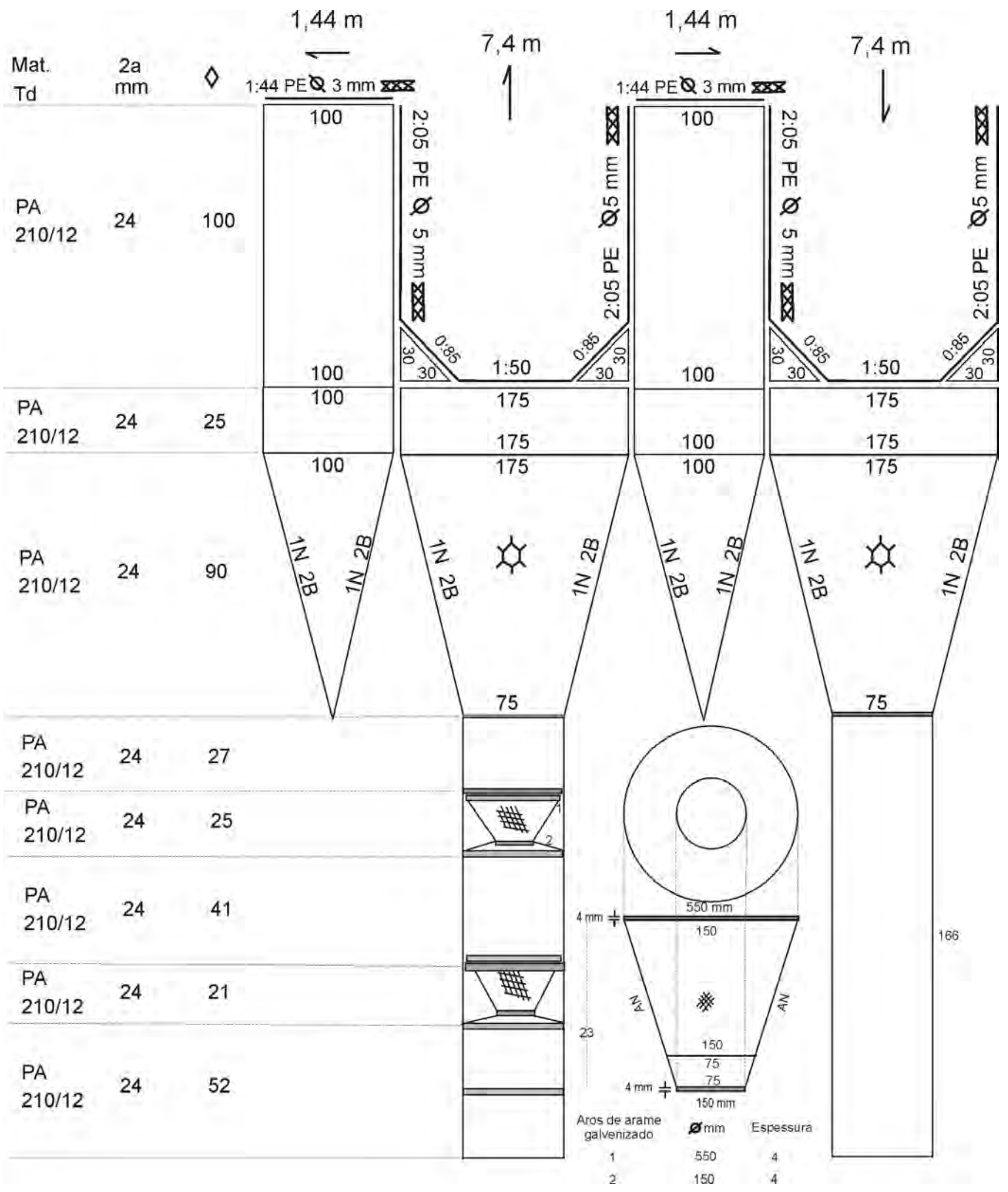

Figura 03. Rede de saquinho com corpo confeccionado com malhas crescentes 


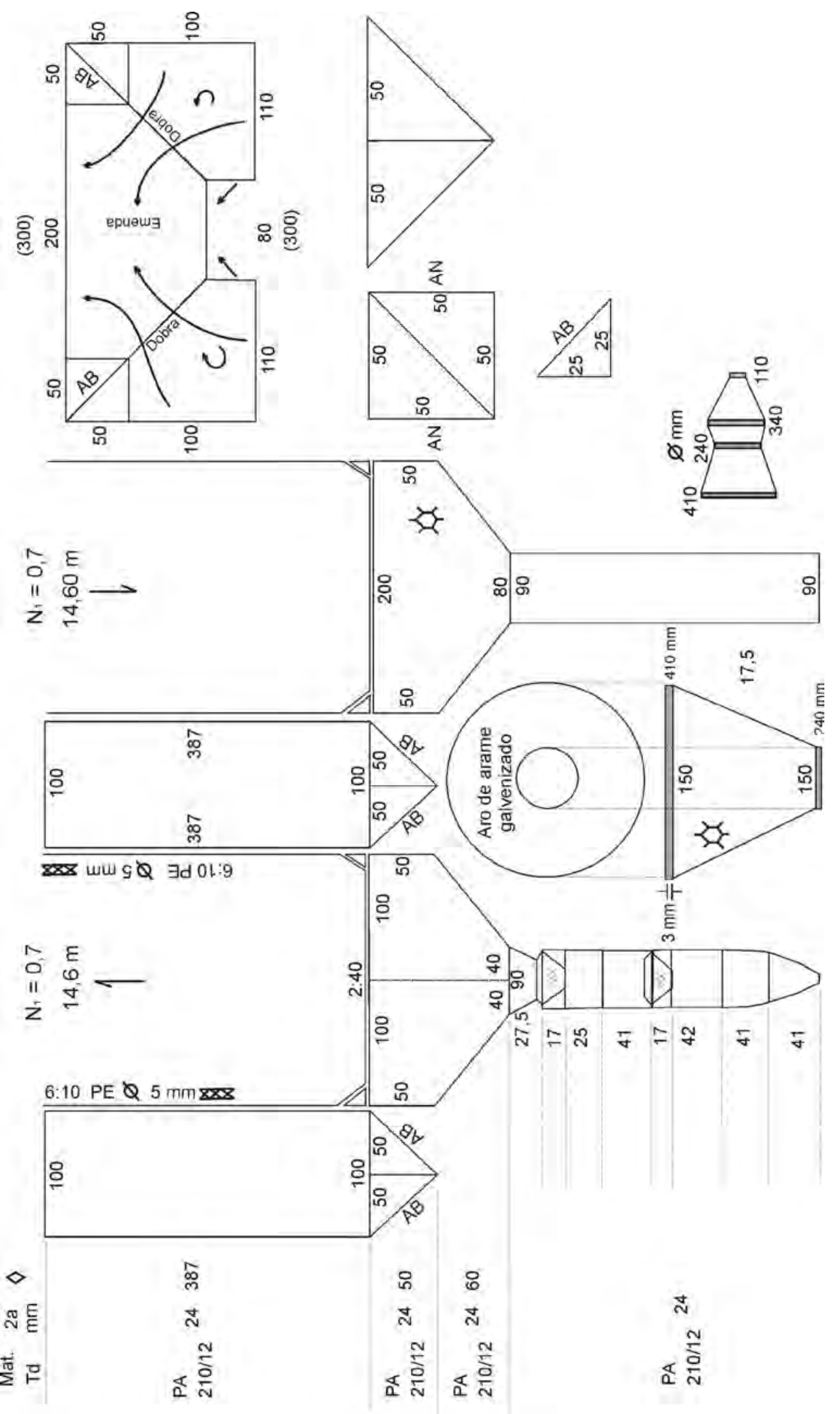

Figura 04. Rede de saquinho com o pano do corpo tipo envelope.

A panagem da rede é confeccionada em poliamida (PA) multifilamentado, com ou sem nó $(210 / 8,210 / 9$ ou $210 / 12)$ e a malha pode variar de 20 a $26 \mathrm{~mm}$ (2a) com predominância das malhas menores no ensacador.

Existem basicamente dois tipos de confecção 
das redes: o tipo crescente (Fig. 03), que possui o corpo com cortes laterais; e o tipo envelope (Fig. 04), onde o corpo é confeccionado com dobra do pano.

Existe uma grande variedade de panos e cabos no mercado voltados para a construção de redes e os pescadores escolhem o material pelo preço. O pano é o principal item de custo na confecção de uma rede, por isso, as redes construídas em PA multifilamentado são, na maioria, confeccionadas com pano usado, oriundo de redes de cerco (traineiras), adquiridos em lojas do ramo ou entrepostos de pescado, comercializados por $\mathrm{kg}$, diferentemente dos panos novos, vendidos somente por metro ou fardo (inteiro). As traineiras usam panos diferentes de barco para barco, diferenciados, principalmente, pela espessura dos filamentos e tamanho de malha. Estas diferenças são refletidas nas redes artesanais.

As mangas são entralhadas em cabo de polietileno multifilamentado (PE) 5 a $8 \mathrm{~mm}$. Possuem de 12 a 26 m de comprimento e 100 a 180 malhas de altura. $\mathrm{Na}$ tralha superior e na inferior são dispostos flutuadores de isopor e lastros de chumbo, respectivamente, responsáveis por armarem a parte posterior da rede. O peso dos lastros e o número de flutuadores (tipo pescada) estão ligados ao tamanho da rede.

\subsection{Rede de saco - Stow Nets}

A rede de saco é a arte de pesca mais antiga em uso no estuário. Recebe este nome pela característica de captura, na qual o camarão fica "ensacado". Amplamente utilizada até a década de 80 , atua hoje em número reduzido devido ao grande sucesso da rede de saquinho.

É uma rede fixa, que se mantém armada em função da correnteza de vazante, capturando os camarões que estão em movimento na coluna d'água, funcionando como um grande filtro. Possui formato cônico como uma rede de arrasto, mas disposto sem mangas.

A pesca com essa arte é restrita às zonas de canal com profundidades de 3 a $14 \mathrm{~m}$. Algumas áreas de canal não podem ser aproveitadas para a colocação dessas redes por serem canais de navegação as quais são proibida por lei. As tralhas são amarradas em argolas feitas de corda ou ferro, presas aos calões, os quais estão dispostos um ao lado do outro com intervalos de 5 a $8 \mathrm{~m}$, dependendo da abertura horizontal da rede. Os calões são estacas de eucalipto, grossas o suficiente para suportarem as fortes correntezas às quais essas redes são submetidas. São colocados com auxílio de uma bomba de pressão motorizada e medem de 6 a $18 \mathrm{~m}$, dependendo da profundidade a serem colocadas. Nos locais de maior profundidade e com correnteza forte, são escorados com o auxílio de cabos e outros calões.

As redes de saco são armadas em distintas profundidades, ou seja, podem ser movimentadas verticalmente em diferentes profundidades melhorando o rendimento. Muito utilizada durante o período noturno sem o emprego de atrativo luminoso e em algumas oportunidades durante $o$ dia.

A despesca é feita a bordo do caíco e o pescado é transferido posteriormente para o bote ou chalupa. São feitas vistorias periódicas durante o período de pesca para evitar uma sobrecarga e um possível rompimento da rede.

Entre os calões, são amarradas cordas que auxiliam a movimentação do caíco, chamadas de "vai-e-vem". As redes ficam dispostas uma ao lado da outra, formando andainas que podem ter até 90 redes.

As redes de saco (Fig. 05 e 06) possuem 8 a $10 \mathrm{~m}$ de boca e comprimento total de até $12 \mathrm{~m}$. A abertura vertical (altura) é no máximo de $5,5 \mathrm{~m}$ e é regulada no momento da pesca, o que vai depender da disposição das tralhas no calão. As tralhas são de cabo de PE ou PP com 5 a $8 \mathrm{~mm}$, sem lastros ou flutuadores.

Normalmente é confeccionada com pano Equiplon (55\% poliamida e $45 \%$ polietileno) com malhas (2a) de 24 e $30 \mathrm{~mm}$ e fio 4 e 3 , respectivamente.

A malha maior é preferencialmente utilizada no corpo e a menor no ensacador. São encontradas também redes confeccionadas em PA 210/12 e $210 / 18$ com malhas de 24 e $26 \mathrm{~mm}$. 


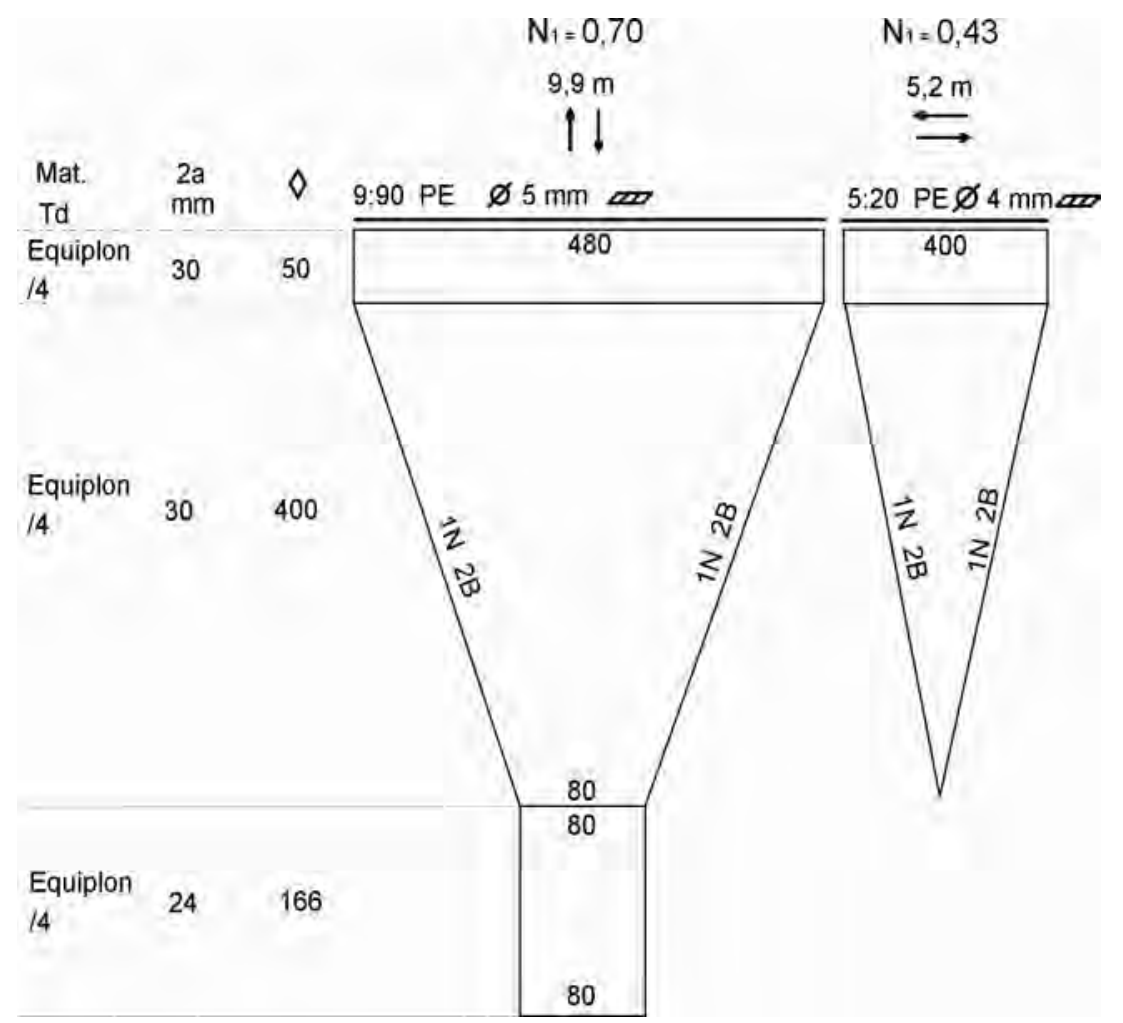

Figura 05. Rede de saco com o corpo formada por quatro panos.

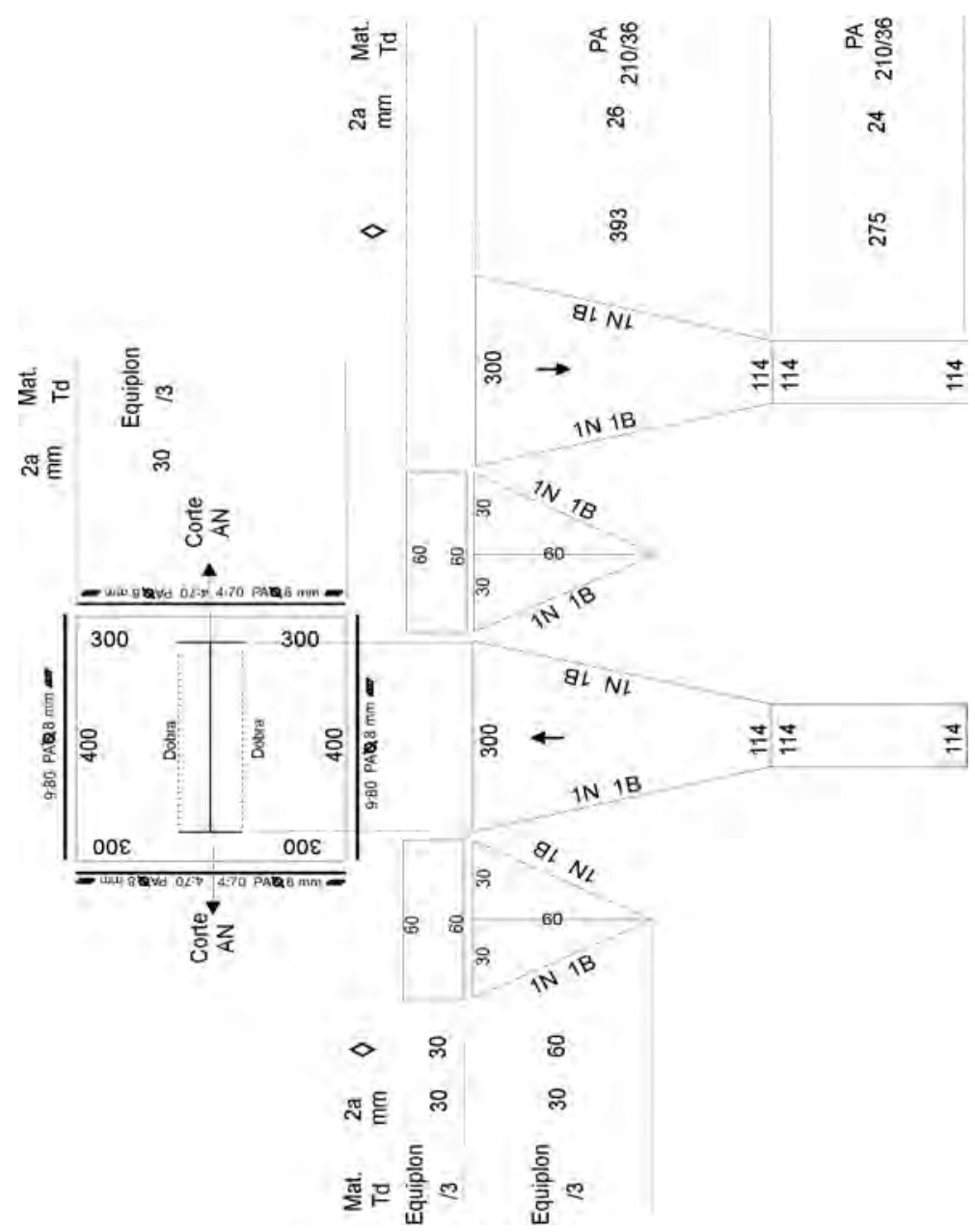

Figura 06. Rede de saco com corte interno no primeiro pano para a colocação do corpo. 


\section{Artes ativas}

\subsection{Rede de coca - Beach Seines}

A coca é uma adaptação de uma rede muito utilizada antigamente na região, chamada rede de calão. Na coca, foi adicionado um ensacador, prolongando o tamanho da rede e aumentando a eficiência de captura.

Os arrastos são manuais e ocorrem em regiões próximas às áreas urbanas em profundidades de 0,6 a $1,5 \mathrm{~m}$ em fundos de areia e/ou areia lamosa, realizados, preferencialmente, a noite com o uso de um lampião a gás que, além de atrair os camarões, também ajuda a iluminar a despesca.

A despesca ocorre com ajuda de um caíco ou flutuador, que pode ser uma bóia de câmara de pneu de caminhão, pedaços de isopor ou balsas feitas de garrafas tipo pet, amarrados a rede ou puxados por um pescador. No flutuador, além do liquinho, são dispostos monoblocos para a seleção e armazenamento do camarão.

A coca (Fig. 07, 08 e 09) é confeccionada com panagem de PA (multifilamento) 210/9, 210/12 ou $210 / 18$, com ou sem nó e malhas (2a) entre 16 e 24 $\mathrm{mm}$. A abertura horizontal (boca) da rede varia de 2,7 a $5,4 \mathrm{~m}$ com altura média de $1,2 \mathrm{~m}$

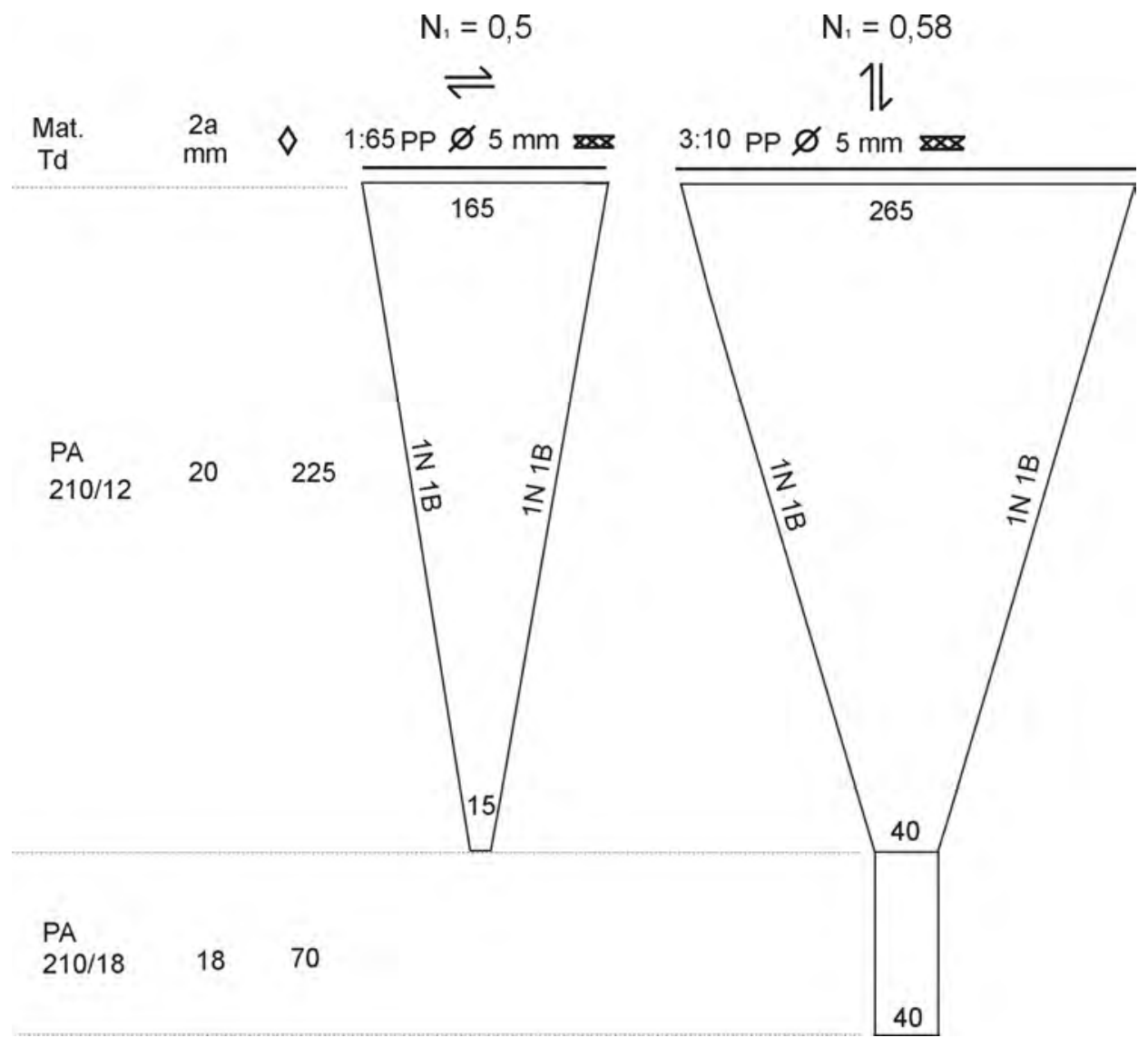

Figura 07. Rede de arrasto de coca com o corpo confeccionado com quatro panos. 


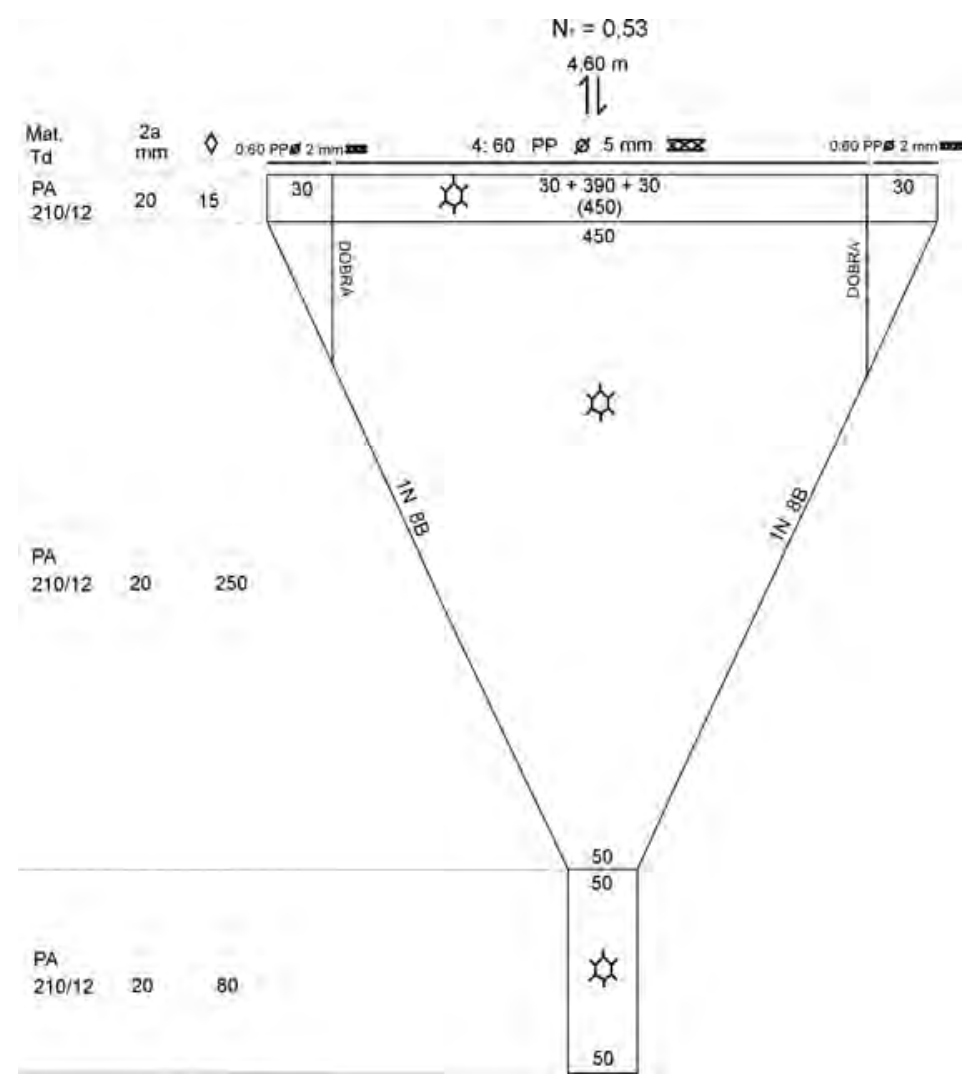

Figura 08. Rede de arrasto de coca com o corpo confeccionado com dois panos.

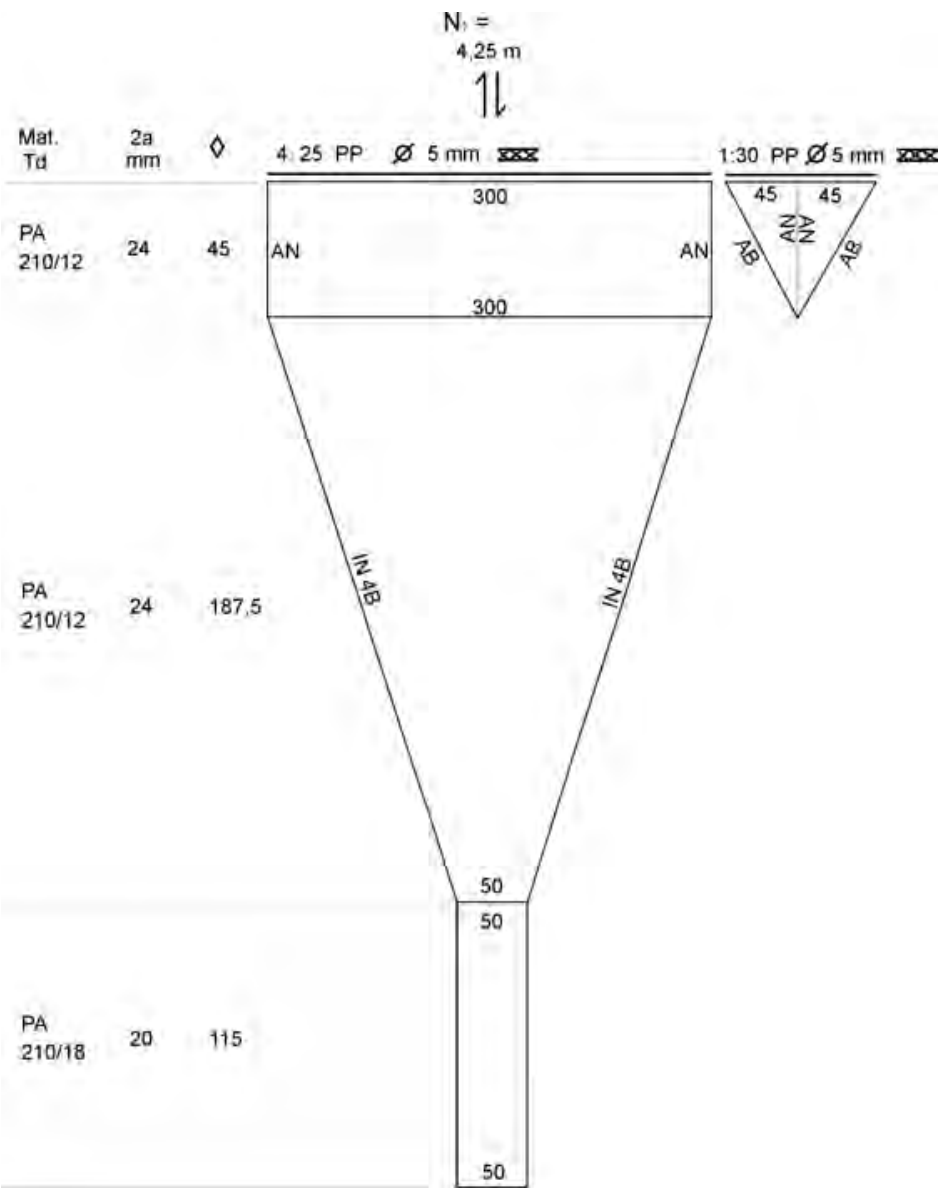

Figura 09. Rede de arrasto de coca com panos laterais inseridos no início do corpo para ganho abertura vertical. 
As redes de coca apresentam diferenças estruturais na sua confecção; com a construção do corpo baseado na união de quatro panos (Fig. 07), a confecção a partir de dois panos (Fig. 08) ou ainda a colocação de dois panos laterais na parte inicial do corpo para uma melhor abertura vertical (Fig. 09).

As tralhas são de cabo de PE ou PP com diâmetro de 4 a $8 \mathrm{~mm}$. Na tralha inferior são colocados lastros e na superior o uso de flutuadores é facultativo. Nas extremidades do corpo da rede (boca) são amarradas estacas de bambu ou madeira responsáveis pela abertura vertical e pelo qual a rede será puxada.

Para facilitar o arrasto, pode-se utilizar um cabo amarrado ao calão e a cintura chamado de "puxador". Cada arrasto é realizado com duas a quatro pessoas durante 30 a 45 minutos.

\subsection{Rede de berimbau}

O berimbau é uma arte de arrasto manual. Em outros estados do sul do Brasil é conhecida como gerival. O princípio de funcionamento da rede se dá pelo arrasto da tralha inferior no substrato formando uma barreira para os camarões. Estes penetram na rede em movimentos contínuos de saltos, chegando até a parte posterior da rede (ensacador) onde ficam aprisionados.

A pesca pode ser efetuada com até 6 redes usadas lado a lado. Para isso é empregada uma embarcação (caíco ou bateira) onde é colocada uma haste de madeira onde as redes são fixadas. A pesca pode realizada manualmente com uma ou duas redes, sendo utilizada uma haste de madeira com uma rede fixada em cada uma de suas extremidades.

Cada arrasto leva de 30 a 60 minutos e não apresenta seleção do pescado, pois captura, praticamente, a espécie alvo. Atua nas mesmas profundidades e locais que a rede de coca. $\mathrm{O}$ uso ilegal é favorecido por se tratar de uma arte que possibilita o arrasto manual e possuir baixo custo operacional.

O aprisionamento do pescado é devido à presença de um funil (ratoeira) semelhante ao utilizado nas redes de saquinho. $O$ funil é formado por dois aros, um maior $( \pm 55 \mathrm{~cm})$, de sustentação do ensacador e o outro, menor $( \pm 6 \mathrm{~cm})$, que forma a extremidade do funil. Podem ser de PVC ou de arame galvanizado.

A rede (Fig. 10 e 11) é formada por um corpo e um ensacador, lembrando uma tarrafa. $O$ ensacador possui um dispositivo anti-fuga, chamado de alçapão (funil) que tem como função impedir o retorno dos camarões aprisionados para o corpo da rede. As malhas podem ser confeccionadas manualmente com monofilamento de nylon (PA) de 0,3 $\mathrm{mm}$ (berimbau catarina) ou com panos de PA multifilamentado $210 / 12,210 / 9$ ou $210 / 8$. 


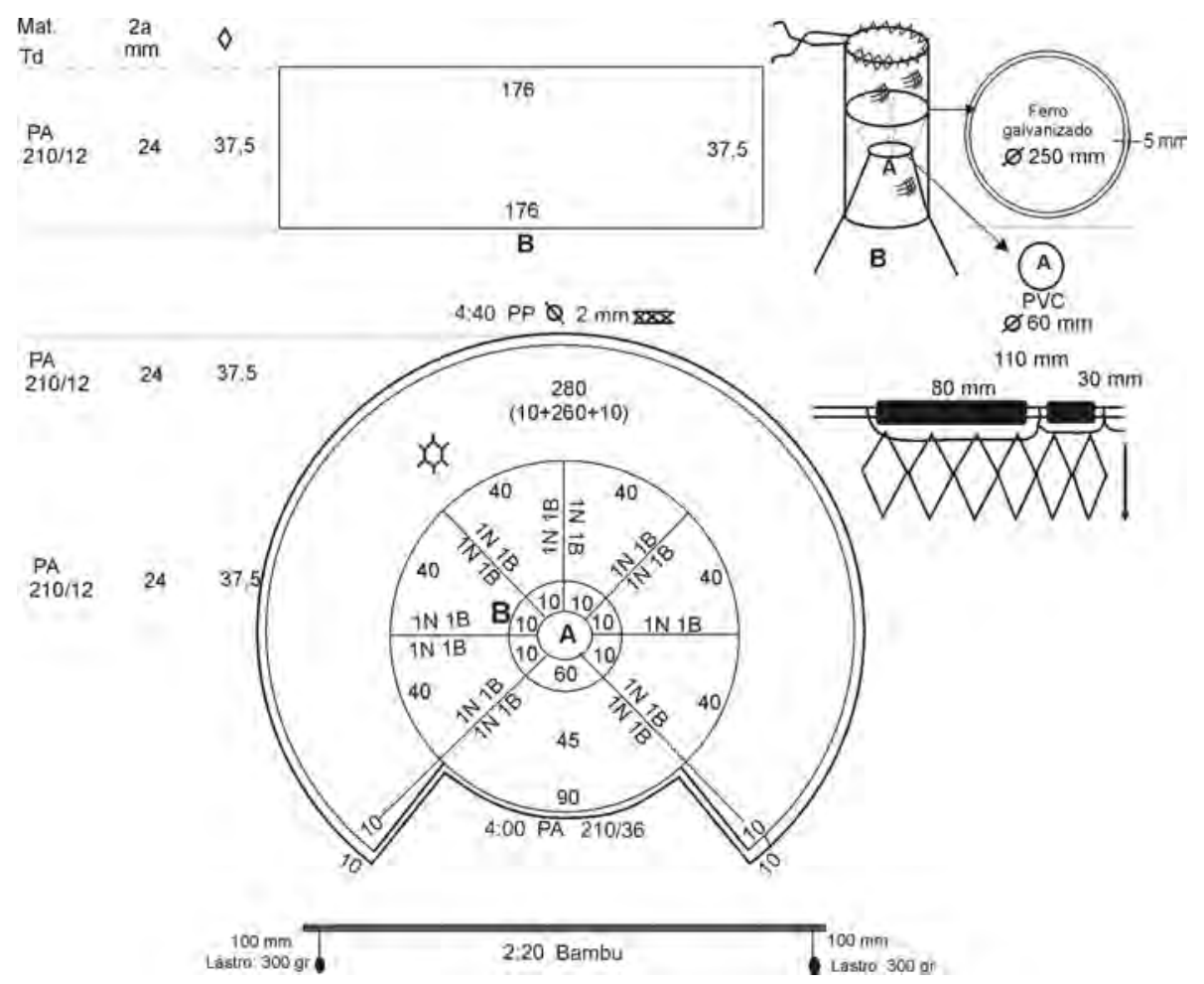

Figura 10. Rede de berimbau confeccionada em PA (multifilamento) com a inserção de diferentes panos para ganho de malhas e, conseqüentemente, aumento gradual do raio da circunferência.

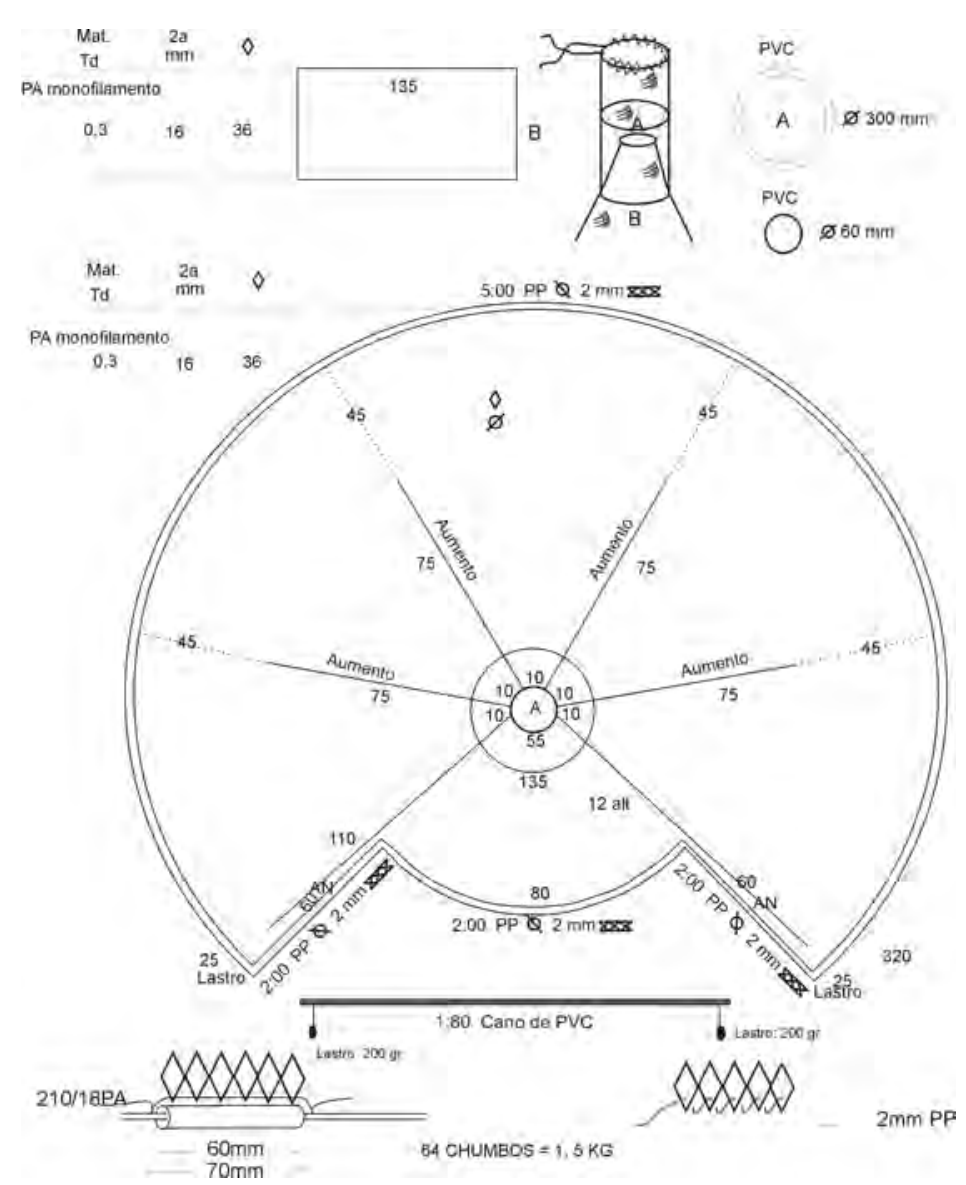

Figura 11. Rede de berimbau (catarina) com as malhas tecidas manualmente com monofilamento de nylon (PA) com aumento do raio da circuferência realizado através do aumento do número de malhas de cada fileira até a altura de 75 malhas. 
Na porção frontal do corpo é entralhado um bambu ou cano de PVC que tem como função deixar essa parte esticada a uma distância de 30 a $40 \mathrm{~cm}$ do substrato, formando uma entrada por onde os camarões passam. $\mathrm{Na}$ porção posterior, são colocados lastros de chumbo em toda extensão. A tralha é de cabo PP (2 a $4 \mathrm{~mm})$.

O tamanho de malha utilizado é extremamente variado, podendo ser encontradas redes confeccionadas com nylon monofilamento com malhas (2a) de 14 a $20 \mathrm{~mm}$ no corpo e ensacador e de 16 a $24 \mathrm{~mm}$ em redes de PA. Ambas as redes possuem a porção do ensacador com menor tamanho de malha.

\subsection{Rede de arrasto de portas - Otter trawls}

A rede de arrasto foi a arte ilegal mais comum na região. Essa arte de pesca mostrou-se também como aquela com maior variação de modelos. Essa grande variedade pode ser explicada pelos diferentes ambientes em que essas redes trabalham no estuários e também pela variedade de espécies alvo que podem capturar. O corpo da rede pode ser projetado para capturar mais de uma espécie. Quando migram para outro tipo de pescaria, trocam somente a parte terminal (rabicho) com a malha adequada a espécie alvo, diminuindo custos operacionais.

O arrasto de portas é caracterizado pela utilização de duas portas presas às asas do apetrecho. É um arrasto realizado por uma embarcação motorizada que puxa as portas que tem a função de realizar a abertura horizontal da rede.

$\mathrm{O}$ arrasto é praticado ao longo de toda a região e, preferencialmente, sobre fundos moles (de lama ou areia), com pouca vegetação e em profundidades que variam de 1,5 a $14 \mathrm{~m}$. Amplamente utilizada na região estuarina, embora proibida. em abril de 1999 foram contadas 43 unidades operando na região entre Pelotas e a llha da Torotama.

A pesca inicia com o lançamento do ensacador na água até a rede ficar estendida para posterior lançamento das portas, que são lançadas em tempos distintos para evitar o enrolamento.

Os arrastos podem ser realizados tanto durante o dia como à noite com duração de 35 a 60 minutos cada, podendo ser feitos pequenos arrastos de 15 minutos para a avaliação da abundância do local. Os processos de lançamento e recolhimento da rede são manuais, realizados por 2 ou 3 pescadores. A seleção do pescado ocorre logo após a despesca ou durante a realização do próximo arrasto.

$\mathrm{Em}$ alguns casos uma única rede pode ser tracionada por duas embarcações, aumentando a força de arrasto, o que permite trabalhar melhor, com mais peso, sobre fundos vegetados.

A rede de arrasto de portas (Fig. 12, 13, 14 e 15) é dividida em manga, corpo e saco (rabicho). $O$ tipo de pano utilizado pode ser PA multifilamento (210/12) com ou sem nó e malhas (2a) de 24 a 30 $\mathrm{mm}$ no ensacador ou ainda de 24 a 36 no corpo e manga da rede. Podem ser encontradas redes confeccionadas com pano de PE 30/6 e malha $36 \mathrm{~mm}$ no corpo. Na asa e no ensacador pano de PA com malha 24 ou $30 \mathrm{~mm}(210 / 12)$. 
RAMON AUGUSTO BENEDET, DENIS DOLCI \& FERNANDO D'INCAO

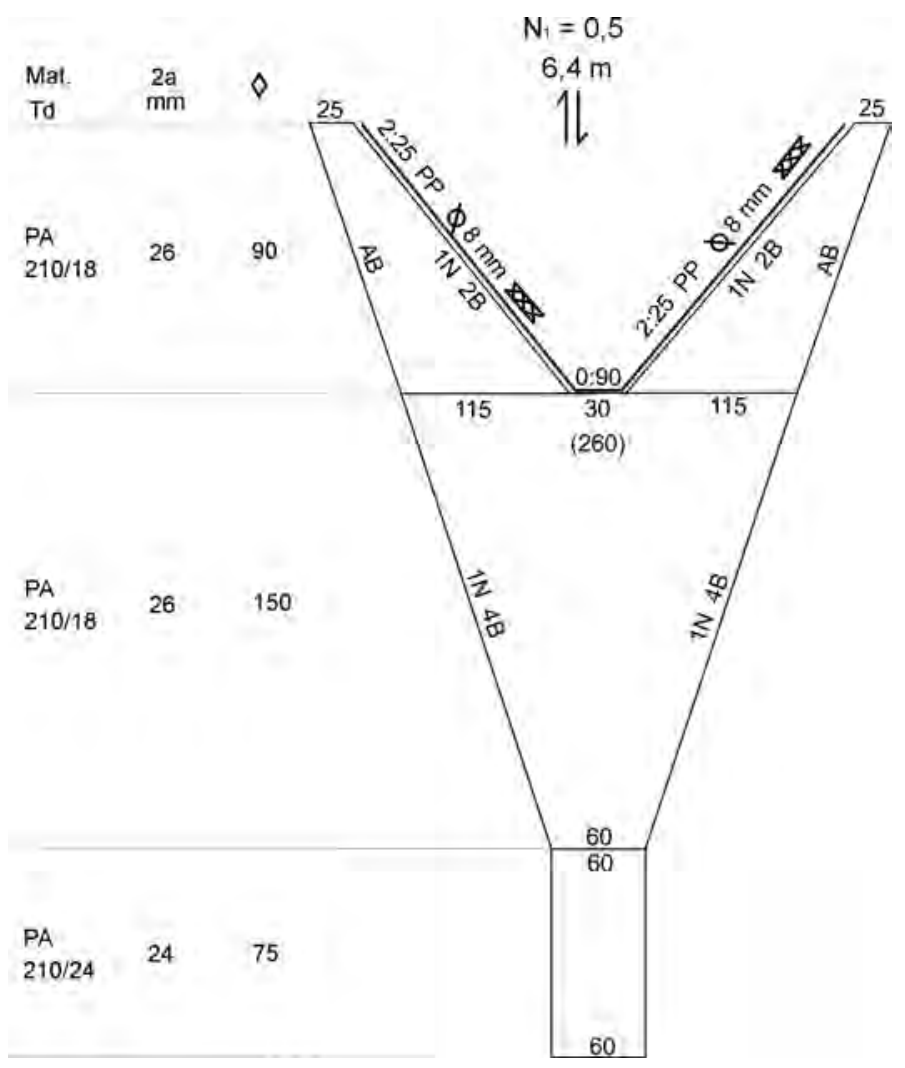

Figura 12. Rede de arrasto de portas.

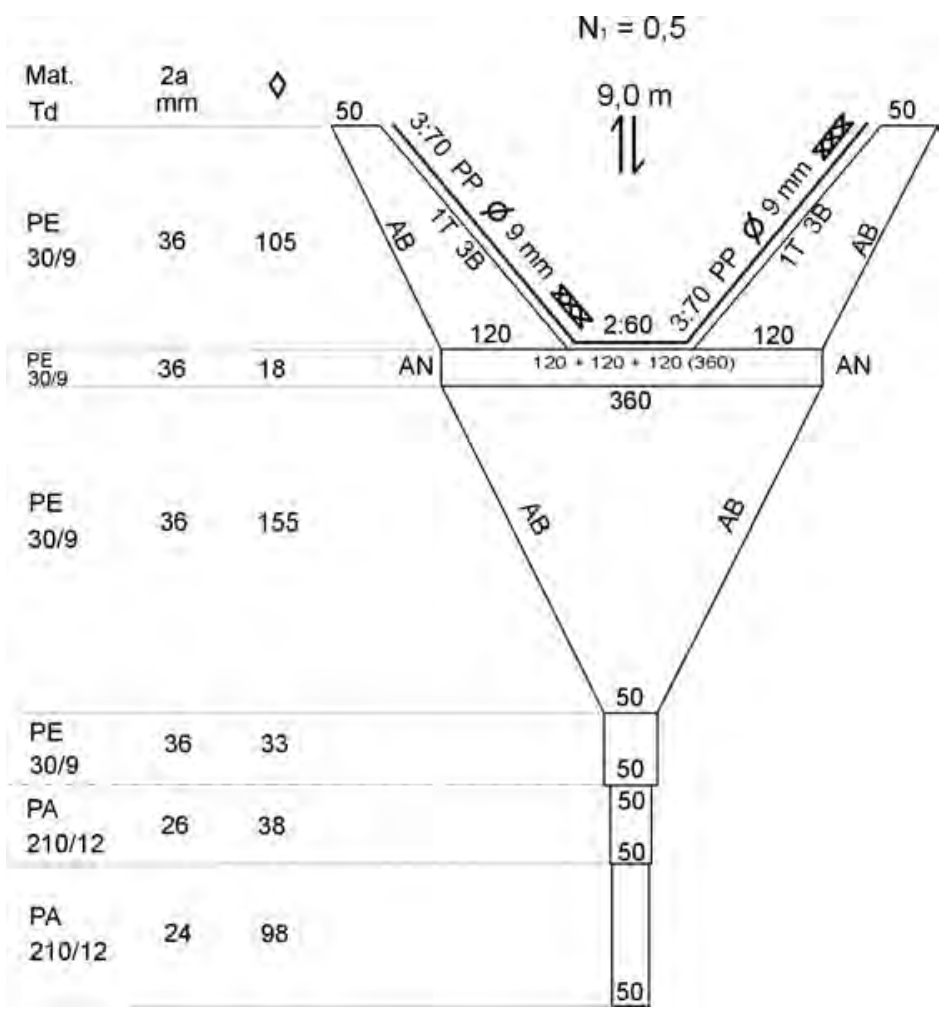

Figura 13. Rede de arrasto de portas. 


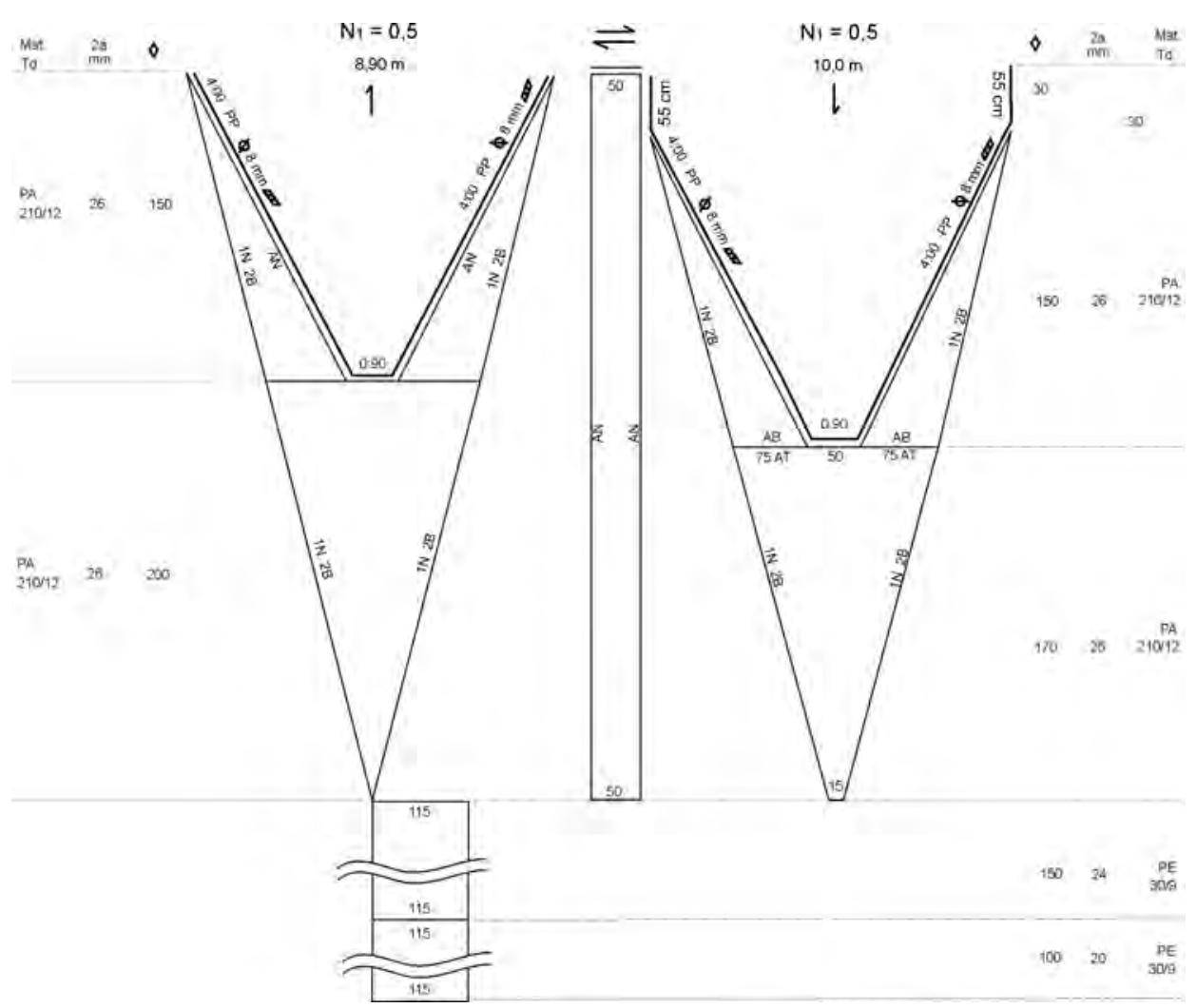

Figura 14. Rede de arrasto de portas confeccionada com quatro panos e uso de recuo do pano inferior.

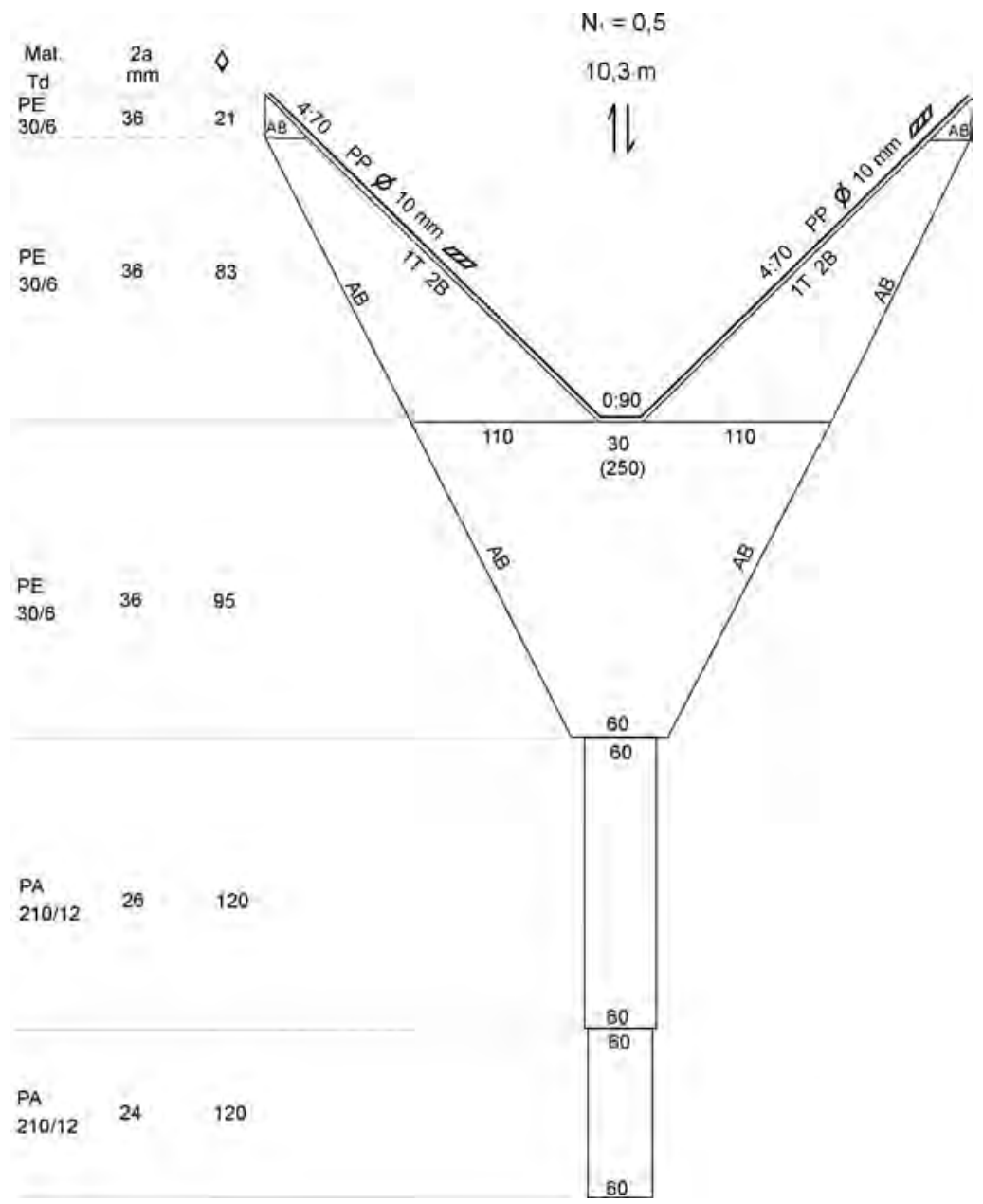

Figura 15. Rede de arrasto de portas. 
As tralhas são de cabo tipo polipropileno (PP) 8 a $10 \mathrm{~mm}$. Na tralha superior são colocados flutuadores de isopor para que a rede tenha abertura vertical e, na inferior, são usadas correntes (pesos) para que ela trabalhe removendo a parte superior do substrato. O peso varia conforme as dimensões da rede e as características do substrato, podendo ser adicionados pesos extra para fundos inconsolidados. São utilizados de 5 a $8 \mathrm{~kg}$ por rede.

Em algumas redes pode ser observada a presença de um cabo amarrado a um pequeno flutuador (isopor ou garrafa pet) e ao ensacador, chamado de "cachorro". Este é utilizado como medida de segurança caso os cabos sejam rompidos acidentalmente (pegadouro) ou intencionalmente quando os pescadores cortam os cabos reais devido à uma possível aproximação da fiscalização. Desta forma, o flutuador pode ser achado, posteriormente, e a rede recuperada.

As portas (Fig. 16) são construídas de acordo com as características da embarcação e da rede. A parte central é de madeira, parafusada em uma armação de ferro (sapata) e medem de $60 \times 35$ a 130 x $55 \mathrm{~cm}$ pesando de 8 a $40 \mathrm{~kg}$, sendo as de 12 a 18 $\mathrm{kg}$ as mais utilizadas pela frota artesanal.

\section{Plano frontal}

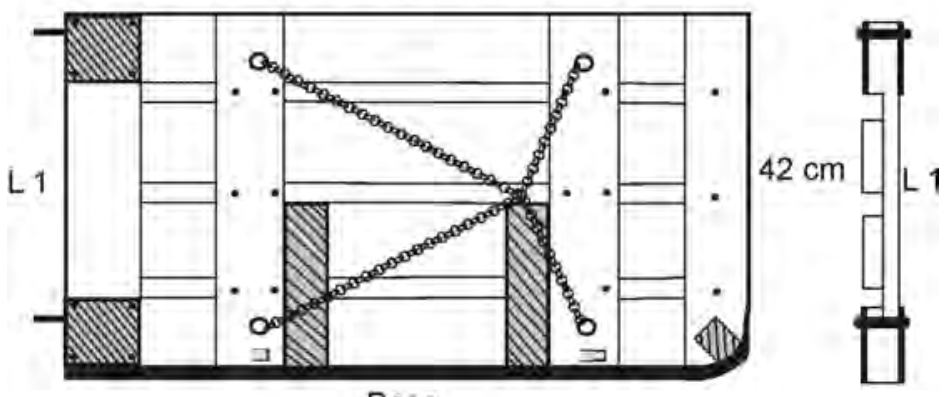

Base

$84 \mathrm{~cm}$

Plano de fugal

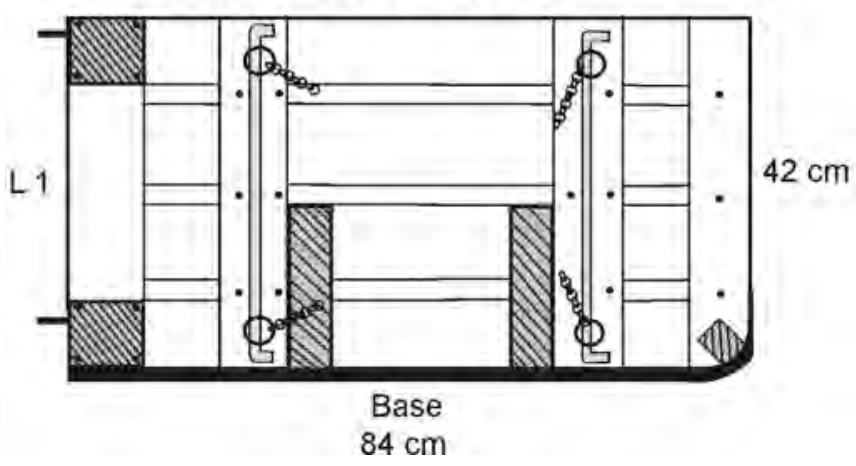

Figura 16. Modelo de porta utilizada nas redes de arrasto (15 kg).

Os cabos (reais) são amarrados ao ílio ou "péde-galinha". O ílio é o sistema mais utilizado, composto por quatro correntes que se prolongam da base da porta até um elo onde são presas. As correntes têm como função regular o ângulo de ataque. No elo, é amarrado um cabo tipo poliéster (PES) 12 ou $14 \mathrm{~mm}$ que é preso na parte lateral interna dos botes ou, de forma reduzida, em pequenos tangones.

\subsection{Rede de arrasto tipo pauzinho - Psin Trawls}

A rede de pauzinho era amplamente utilizada nos baixios (1,5 a $4 \mathrm{~m})$ da região nas décadas de 70 e 80 , mas encontra-se em desuso pelo alto custo operacional e pela popularização da rede de arrasto simples. Caracterizada pelo uso de um calão ou uma estrutura de ferro (pé de pato) em cada extremidade da rede, puxadas por duas embarcações motorizadas com um caíco de reboque, assemelhando-se a um arrasto de parelha.

Os arrastos são realizados durante o dia com duração de até uma hora. Nas extremidades da rede (boca) são amarradas duas estruturas (Fig. 17) chamadas de pau ou pé-de-pato, responsáveis por 
manter a rede armada. Nessa estrutura, são amarrados dois cabos, um na parte superior e outro na inferior formando uma tesoura que vai formar um único cabo a ser puxado pela embarcação. Ainda nessa estrutura, é amarrado um terceiro cabo que vai ser usado para rebocar um caíco. Este cabo é chamado de "cisga" e tem o comprimento necessário para que o caíco fique sob a parte final do ensacador de onde sai um pequeno cabo, que é amarrado no caíco e serve para o içamento do ensacador para realizar a despesca. O processo de despesca é feito somente com o içamento do ensacador e pode ser realizado com as redes em movimento. O lançamento da rede também é efetuado pelo caíco e pode ser realizado por um ou dois pescadores.

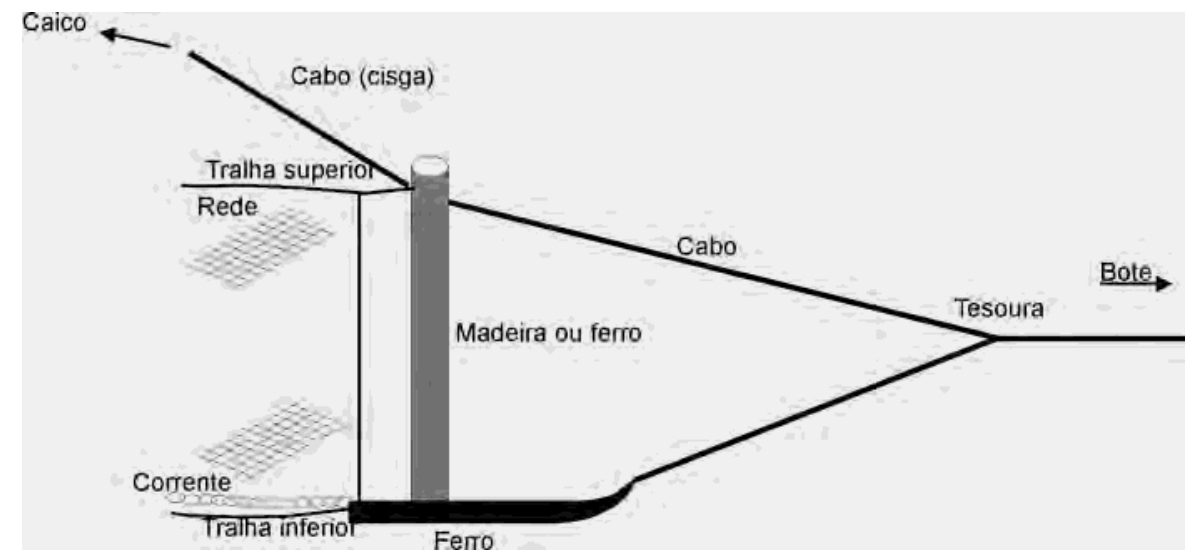

Figura 17. Conjunto de estruturas utilizadas no arrasto de pauzinho.

A rede de pauzinho (Fig. 18 e 19) apresenta algumas características semelhantes com a rede de coca. Tipos de corte no pano e o material utilizado na confecção da rede são exemplos, mas apresentam dimensões maiores, tralhas mais grossas e uma corrente ao longo da tralha inferior cerca de $10 \mathrm{~cm}$ menor que a tralha. A vantagem da utilização dessa rede com relação à rede de portas se dá pela maior abertura horizontal e vertical, capturando também os camarões que não estão junto ao fundo.

Apresenta tamanho de malha (2a) de $24 \mathrm{~mm}$ de PA 210/12 e tende a diminuir na porção final da rede para $20 \mathrm{~mm}$. Possui 5,0 a 9,0 m de boca.

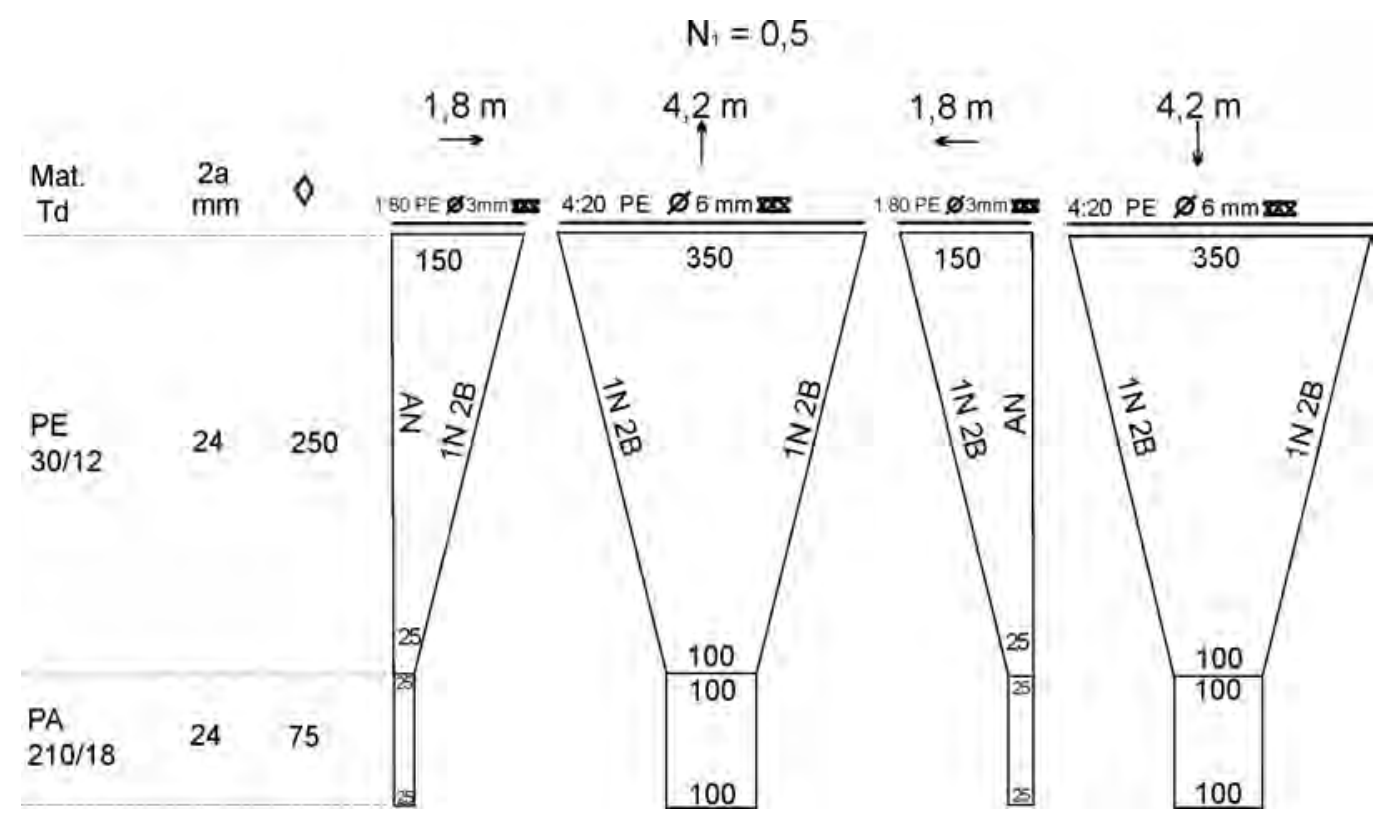

Figura 18. Rede tipo pauzinho, confeccionada com quatro panos no corpo. 


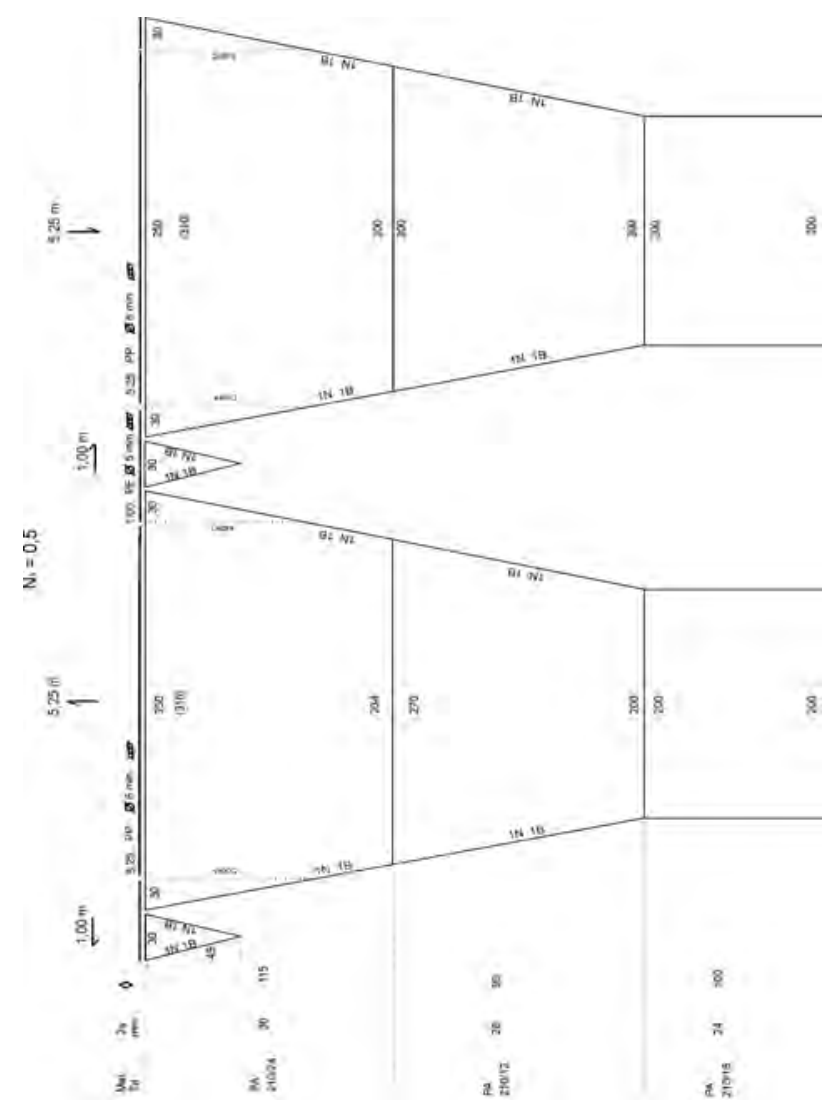

Figura 19. Rede de arrasto de pauzinho com panos laterais inseridos no início do corpo para ganho de abertura vertical.

\section{DISCUSSÃO}

A região estuarina da Lagoa dos Patos é formada por um grande número de enseadas e bancos com baixa profundidade (Calliari, 1980). Essas características permitem o uso de um grande número de artes de pesca e embarcações relativamente simples, evidenciadas também em outras regiões do Brasil (Diegues, 1993b; Chaves \& Robert, 2003), o que facilitou a instalação de diversas comunidades pesqueiras no seu entorno.

A frota de barcos artesanais da região estuarina da Lagoa dos Patos foi descrita em trabalhos anteriores como o de Tagliani \& Costa, 2005. Porém, foram observadas embarcações do tipo caíco com tamanho inferior ao citado e a utilização de uma embarcação até então não descrita, chamada de bateira ou caico catarina.

A rede de saquinho é a mais importante arte de pesca utilizada na região, fato constatado por outros autores (Asmus, 1989; Marques 1997; Almeida \& D'Incao, 1999) que denominam essa rede de aviãozinho. Nesse estudo foi mantida a nomenclatura mais utilizada pelos pescadores artesanais. Essa diferença é explicada pelo fato do nome aviãozinho ter sido adotado inicialmente pelo formato da rede. Com o passar do tempo essas redes tiveram suas mangas (asas) reduzidas para melhorar sua eficiência e foram denominadas de saquinho.

Essas redes utilizam atrativo luminoso, tradicionalmente obtido através de lampiões a gás GLP (P2), recarregados diariamente, fazendo com que a pesca tenha um custo elevado devido ao preço do botijão de gás (P13). Na tentativa de mudar essa realidade, alguns pescadores têm obtido sucesso com a utilização de lâmpadas $12 \mathrm{v}$, conectadas a baterias de carro. Essas baterias podem ser recarregadas com menor custo, diminuindo consideravelmente o gasto envolvido na pesca (Benedet \& D'Incao, 2004).

As redes de arrasto (manuais ou motorizadas), apesar de serem proibídas, foram observadas em todos os anos de estudo, fato relatado também por outros autores na região (D'Incao,1991; Marques, 1997; e Almeida \& D'Incao, 1999). 
Apesar da dificuldade em quantificar os danos causados pela pesca de arrasto, alguns estudos já demonstraram que o descarte pode alterar assembléias de espécies, as relações predador/presa, aumentar recursos alimentares para espécies oportunistas (aves marinhas, cações, golfinhos e outros mamíferos marinhos), modificar a estrutura e função das comunidades bentônicas e aumentar a competição entre pescadores e animais marinhos pelos recursos ainda disponíveis (Jones, 1992; Alverson et al., 1994; Prenna et al., 1999; Hall, 1996, 1999; Clucas, 1997). As mudanças na estrutura das comunidades bentônicas podem ser devastadoras. As portas podem penetrar de 6 a $30 \mathrm{~cm}$ (Alverson et al., 1994) desestabilizando e destruindo muitos organismos da epifauna e infauna. Mudanças causadas pelo descarte e danos físicos causados pelo arrasto tem sido apontadas também, como responsáveis pela redução da fauna de invertebrados (Jones, 1992).

A rede de berimbau é encontrada em outras regiões do país como no litoral do Paraná, Santa Catarina e São Paulo (Gamba, 1984; Mendonça \& Katsuragawa, 2001; Chaves \& Robert, 2003). Na região deste estudo, os pescadores raramente operam essas redes embarcados, pois a embarcação serve simplesmente como apoio/base para a colocação das redes, que neste caso é levemente impulsionada pelo pescador que fica na água.

A intensidade e o tipo de rede utilizada estão relacionados com aspectos meteorológicos. Um exemplo é que ventos fortes restringem o uso das redes de saquinho e arrasto de portas e a ausência de ventos do quadrante norte, aliados ao nível de água na laguna, irá influenciar na colocação das redes de saco que necessitem de força de vazante para atuarem.

\section{LITERATURA CITADA}

ALMEIDA, H.L.P.S. \& D'INCAO, F. 1999. Análise do esforço de pesca do camarão-rosa (Farfantepenaeus paulensis) na Lagoa dos Patos, Brasil. Atlântica, Rio Grande, 21: 77-92.

ALVERSON, D.L.; FREEBERG, M.H.; POPE, J.G. \& MURAWISK, S.A. 1994. A global assessment of fisheries bycatch and discards. FAO Fisheries Technical Paper, 339: 1-233.

ASMUS, H.E. 1989. Estrutura e dinâmica do Sistema Lagoa dos Patos. Secretaria da Comissão Interministerial para recursos do Mar. Comunicado Técnico, 49p.

BENEDET, R.A. \& D'INCAO, F. 2004. Pink shrimp
A atual legislação é falha quanto às características técnicas das redes utilizadas legalmente para a pesca, principalmente, nas redes de saquinho, pois não delimitam uma relação entre a altura de malhas do pano do ensacador e o diâmetro dos aros (utilizados para dar sustentação ao ensacador). Isso faz com que as redes (ensacador) sejam confeccionadas muitas vezes com um número maior de malhas do que o necessário, deixando o pano mais solto. Assim pode ser mantido esticado na hora da pesca, diminuindo, consideravelmente, a luz da malha (diâmetro interno). A luz da malha influencia no tamanho do pescado capturado. Quanto menor a luz da malha, menor será o tamanho mínimo de captura (FAO, 1992).

Assim, a maneira como o pano é disposto no ensacador faz com que a forma de diamante seja mantida e, conseqüentemente, os valores do coeficiente de abertura sejam facilmente diminuídos, principalmente se for exercida uma pressão com o intuito de manter a rede o mais esticada possível.

Diante desses aspectos abordados, faz-se necessário um amplo estudo de seletividade dessas redes, tendo em vista que o único estudo dessa natureza foi realizado há mais de 20 anos (Rahn in SUDEPE-PDP, 1985 apud D'Incao, 1991). Além disso, aconselha-se o estudo da viabilidade da implementação de outras artes de pesca mais seletivas, que capturem uma menor quantidade de juvenis de peixes.

\section{AGRADECIMENTOS}

Os autores agradecem aos pescadores artesanais e redeiros que colaboraram com valiosas informações para a realização do trabalho e aos tripulantes da lancha Larus Paulo Arede e Edgar pela ajuda nas saidas.

(Farfantepenaeus paulensis) fishery at Patos Lagoon estuary, RS, Brazil. In: 3rd Brazilian Crustacean Congress The Crustacean Society Meeting, 2004, Florianópolis. Sociedade Brasileira de Carcinologia, 2004. v. 1. p. 119-119.

CALLIARI, L.J. 1980. Aspectos sedimentológicos e ambientais da região sul da Lagoa dos Patos. Dissertação, UFRGS, Porto Alegre. 190p.

CHAVES, P.T. \& ROBERT, M.C. 2003 Embarcações, artes e procedimentos da pesca artesanal no litoral sul do Estado do Paraná, Brasil. Atlântica, Rio Grande, 25(1): 53-59.

CLUCAS,I. 1997. A study of the options for utilization of bycatch and discards from marine capture fisheries. FAO Fisheries 
Circular, 928: 1-59.

COUTINHO, R \& SEELIGER, U. 1986. Seasonal occurrence of benthic algae in the Patos Lagoon estuary, Brazil. Estuarine Coastal Shelf Science, 23: 889-900.

DIEGUES, A.C.S. 1993a. O movimento social dos pescadores artesanais brasileiros. CEMAR, USP, São Paulo, 22p. (Série Documentos e Relatórios de Pesquisa $\mathrm{n}^{\circ}$ 8)

DIEGUES, A.C.S. 1993b. Realidades e falácias sobre pescadores artesanais. CEMAR, USP, SP, 15p. (Série Documentos e Relatórios de Pesquisa no 7)

D'INCAO, F. 1991. Pesca e biologia de Penaeus paulensis na Lagoa dos Patos, RS. Atlântica, Rio Grande, 13(1): 159-170.

FAO, 1992. Catalogue of small scale fishing gear; 2nd edition (multi-lingual) Fishing News Books; UK. 112p.

FERNÖ, A. \& OLSEN, S. (Eds.) 1994. Marine fish behaviour in capture and abundance estimation. Fishing News Books, $221 \mathrm{p}$.

GAMBA, M.R. 1984. Guia prático de tecnologia de pesca.

CEPSUL/IBAMA, Itajáí, 49p.

HALL, M.A. 1996. On bycatches. Reviews in Fish Biology and Fisheries, 6(3): 319-352.

HALL, M.A. 1999. The effects of fishing on marine ecosystems communities. Blackwell Science Ltd. London, 274p.

JONES, J.B. 1992. Environmental impacto of trawling on the seabed: a review. New Zealand Journal of Freshwater Research, 26: 59-67.

MARQUES, W.M. 1997. Estimativa da rejeição da pesca do camarão-rosa Penaeus paulensis com "aviãozinho" no estuário da Lagoa dos Patos (RS), Brasil. Dissertação, FURG, Rio Grande. 174p.

MENDONÇA, J.T. \& KATSURAGAWA, M. 2001. Caracterização da pesca artesanal no complexo estuarino-lagunar de CananéiaIguape, Estado de São Paulo, Brasil (1995-1996). Acta Scientiarum, Maringá, 23(2): 535-547.

NÉDÉLEC, C. \& PRADO, J. 1990. Definition and classification of fishing gear categories. FAO Fisheries Technical Paper 222 Rev.1. FAO Document, Rome. 92p.

PRENNA, J.; SCHWINGHAMER, P.; ROWELL, T.W.; GORDON JR., D.C.; GILKINSON, K.D.; VASS, P. \& MCKEOWN, D.L. 1999. Experimental otter trawling and a sandy bottom ecosystem of the Grand Banks of Newfoundland: analysis of trawl bycatch and effects on epifauna. Marine Ecology Program Series, 181: 107-124.

TAGLIANI, P. \& COSTA, A.A. 2005. Sustentabilidade da atividade de pesca artesanal no município do Rio Grande/RS. In: E.G. Reis (coord). Restabelecimento da capacidade produtiva do sistema Ambiental da Pesca artesanal no extremo sul do Brasil. FNMA, 789p. 